\title{
Creating contemplative studies in the Southwest: theory and practice
}

\author{
Andrew O. Fort
}

Correspondence: a.fort@tcu.edu Texas Christian University, Fort Worth, USA

\begin{abstract}
In this article, I offer a brief history of the Contemplative Studies initiative at Texas Christian University, then discuss some of the theoretical underpinning for our program, indicating the value of contemplative pedagogy in academia and Religious Studies in particular. I argue that such pedagogy addresses central concerns of liberal arts education, that is, enhancing insight into and critical reflection about both self and others in their social and historical location. Contemplative learning adds "first person" direct experience to traditional "third person" objective study which gives a more accurate (and "lived") understanding of both one's own and others' worldviews and practices. I will also discuss how and why students themselves want contemplative methods in the classroom. Religion professors in particular should introduce students to the importance of understanding the historical and cultural context of these (and our own) worldviews, enhancing these understandings with appropriate first-hand experience of basic exercises in various traditions (religious and modern secular) that have specialized in "first person" inquiry. I will close by raising questions about how scholars should address the high degree of appropriation, decontextualization, and commodification of most contemplative traditions today.
\end{abstract}

Keywords: Contemplative Studies, Pedagogy, Liberal arts, "First person" inquiry

Contemplative Studies (CS) is an emerging field in many disciplines, and it is a particularly natural fit for the comparative, cross-cultural, and interdisciplinary study of religion, my area of training. Numerous universities throughout the country, including those in the apparently "traditional" Southwest, are beginning to explore CS and how it can enhance liberal arts education in a wide variety of fields. I will cover this topic in two sections: first I will offer a short history of the development of the CS initiative at my university, Texas Christian University (TCU), and briefly in the wider region. I believe this section could serve as a useful starting point for others interested in creating CS programs at their schools. I then will discuss some of the assumptions and theoretical underpinning for this initiative, indicating the value of contemplative pedagogy in academia and Religious Studies in particular. Few would question the traditional detached "third-person" study of contemplative traditions as part of a curriculum, or more broadly the importance of introducing students to profound and long-standing knowledge present in various cultures and texts. More, however, have reservations about the worth and propriety of "first person" contemplative practice. While I have already addressed this elsewhere, ${ }^{1}$ in this paper I again want to argue the value of "first

(c) The Author(s). 2016 Open Access This article is distributed under the terms of the Creative Commons Attribution 4.0 International License (http://creativecommons.org/licenses/by/4.0/), which permits unrestricted use, distribution, and reproduction in any medium, provided you give appropriate credit to the original author(s) and the source, provide a link to the Creative Commons license, and indicate if changes were made. 
person" study for those in the liberal arts, particularly as it enhances insight into and critical reflection about both self and others in their social and historical location. ${ }^{2}$

\section{Part I: starting a program in the region and at TCU}

Two initial workshops set the foundation for the development of CS at TCU and in the Southwest region. After reading about and speaking with some others interested in this emerging field, significantly prompted by the preparation for and publication of the book Meditation and the Classroom (Simmer-Brown and Grace 2011), I organized these two workshops for scholars in the Southwest (the first held at Baylor University in 2011 and the second at Rice University in 2012), both led by Louis Komjathy of the University of San Diego, a co-founder of the CS group of the American Academy of Religions (AAR). The first, funded by the Wabash Center for Teaching and Learning about Religion and an AAR regional development grant, explored the interest in and knowledge about CS in the region, and began a discussion of pedagogical issues relating to teaching CS in liberal arts settings. The enthusiasm produced by this meeting generated a second one, also funded by the Wabash Center. We expanded and deepened the earlier conversation to enhance our abilities to think critically and teach effectively about traditions of contemplation, ${ }^{3}$ to develop best practices for "contemplative pedagogy," and to better articulate, on and beyond our campuses, how courses on or using contemplative practices contribute to a liberal arts curriculum.

One outcome of these workshops was a commitment by a number of participants to look into the development of CS on their respective campuses. To that end, in the spring of 2012 I began conversations about this topic at TCU with a variety of faculty as well as the director of our Center for Teaching Excellence (CTE). We decided to launch a faculty/staff interest group in the fall of 2012, with monthly discussion meetings (including education, practice, and sharing) and one major event with an outside speaker per semester, a structure we continue today. We formed a steering committee, which included two members from the department of Religion, and one each from Anthropology, Modern Dance, Psychology and Student Development Services. Each committee member already had some form of contemplative practice, and we meet at semester beginning and end to review the prior semester's efforts and to plan for the next term. ${ }^{4}$ We were then, and remain today, committed to interdisciplinary approaches (and participants now include faculty from English, Physics, and Business).

With an interdisciplinary committee established, we announced our first panel discussion titled, "What is Contemplative Studies, and what is its place at TCU?" The panel, promoted and supported by CTE staff and advertised through email and informal networks, included short presentations by me and another TCU religion professor, Mark Dennis. We were also joined by Donnalee Dox, a performance studies professor and director of the Religious Studies interdisciplinary program at Texas A\&M, who was also a participant in both of our earlier regional meetings. The panel was followed by a brainstorming session with the twenty-five faculty and staff who attended to see what was possible and desirable at TCU. In addition to introducing CS in this initial workshop, we began relationship building and networking, finalized topics for the meetings that would follow, and committed to a spring event co-sponsored with TCU's Nursing School. One of the most remarkable outcomes of this event was the extent of 
interest shown by faculty and staff in personal practice, and conversely, how few of the faculty had any such practice.

As mentioned above, our small group meetings have generally included both discussion and a shared group practice. Over the years, discussions have focused upon CS as an emerging discipline, the roles of contemplative theory and practice in teaching and research, their relationship with the traditional goals of liberal arts education, and their place in student development, broadly conceived. Other topics discussed include definitions of key terms in CS, ethical issues in teaching contemplative exercises in class, contemplation in a digital era, the role of embodiment (physical and cultural) and the environment on contemplation, how to build interdisciplinary and crosscampus relationships, and personal practices of faculty and staff. We have held lecture style presentations on various aspects of contemplation, ranging from long-standing Asian religious traditions to modern psychology. ${ }^{5}$ Given TCU's heritage and student population, we have also made sure to spend time focusing on Christian contemplation, as well as dispelling the misimpression that contemplative practices are exclusively "Eastern."

Our discussions have also extended to address broader pragmatic applications of contemplative practice in a variety of campus environments. We have, for example, discussed specific classroom practices which would be useful and effective in any course: exercises like sitting in silence or watching the breath for a few minutes at the beginning of class, being present when walking across campus or eating a meal, or bodily awareness practices. ${ }^{7}$

In addition to integrating contemplative exercises in their own classes, steering committee members also led exercises in other faculty members' classes (from Business to Philosophy to Media Ethics) and made presentations to departmental faculty meetings. We have also established weekly meditation sessions sponsored by our Office of Religious and Spiritual life and Brite Divinity School, and a member of the Counseling Center also regularly leads a five-session workshop for students in which he introduces a variety of contemplative practices to address stress, anxiety, and sleep issues.

Finally, we have organized social events promoting CS on campus, including faculty and student panels on personal contemplative practices, movie nights (including the films Kumare, ${ }^{8}$ Samsara, ${ }^{9}$ and Doing Time, Doing Vipassana ${ }^{10}$ ), a number of labyrinth walks, ${ }^{11}$ a contemplative poetry competition co-sponsored with the TCU literary magazine, and various contemplative movement exercises in (and outside of) a dance studio. Together these events have effectively helped "spread the word" about contemplative thought and experience to a diverse audience at and beyond TCU.

\section{Major semester events at TCU}

In addition to our monthly meetings, we have hosted at least one larger event each semester featuring speakers from a wide range of disciplines. Each was intended to offer an expert illumining some new aspect of CS for the TCU community. I will now briefly describe these events (and the people involved in them), in part as examples and suggestions for readers interested in creating CS programs at their universities. As previously mentioned, we co-organized a workshop titled "Wellness and Contemplative Practice in Health Care and Higher Education," with TCU's College of Nursing in 
spring 2013. This workshop addressed the ongoing effects of stress and "multitasking" in contemporary life, and offered possibilities to maximize wellness and help cultivate physical, mental, and emotional balance, both personally and in one's local environment. The speakers were Elissa Epel, professor of psychiatry at UC San Francisco and Alejandro Chaoul, professor in the Integrative Medicine Center at MD Anderson Cancer Center in Houston. Prof. Epel shared her work on the role of stress in aging and how mindfulness-based interventions might slow cellular aging and Prof. Chaoul described his experience with using yoga and meditation with cancer patients. Both discussed some of the methodological issues that their work raises in the humanities and sciences. ${ }^{12}$ This event obviously foregrounded aspects of contemplative studies in health care, and was particularly valuable to start our initiative.

In fall 2013, Louis Komjathy, who is both the co-founder of the CS group in the American Academy of Religion and a Daoist priest, led a workshop on "Imagining the Contemplative University," exploring university education and campus community life in relation to contemplative practice and experience from a multi-disciplinary and diverse curricular perspective. Prof. Komjathy also gave a talk titled, "Studying What One Practices, Practicing What One Studies: A Daoist Professor's Perspective." Here, he pointed out that being an adherent of a religious tradition while working in the field of Religious Studies raises a host of issues, and brings forth a variety of reactions, positive and negative. For example, some hold that "insiders" or practitioners have lost critical distance; others argue that actual practice deepens scholarly insight. He emphasized the potential contributions of the scholar-practitioner to the academic study of religion in general and Daoism in particular, and shared his own "first person" experiences of being both while working in an academic context where "third person" social scientific and secular materialist perspectives dominate. ${ }^{13}$ With this event, we hoped to raise awareness of the unique value of contemplative studies within a traditional liberal arts context.

In spring 2014, we held a major event co-sponsored with TCU's College of Liberal Arts. Here, the former Jesuit priest and now long-time Zen master Ruben Habito, whose formal titles include Professor of World Religions and Spirituality at Southern Methodist University's Perkins School of Theology and Guiding Teacher at the Maria Kannon Zen Center in Dallas, spoke to faculty, students, and community members (many from TCU's affiliated Brite Divinity School) in a lecture titled, "Christian Contemplation and Buddhist Practice-The Spiritual Exercises and Zen." Habito discussed his life journey and new book Zen and the Spiritual Exercises (Habito 2014), which considers the relationship between Zen meditation and the Spiritual Exercises of St. Ignatius Loyola. He eloquently articulated the experience of sitting quietly with full attention bringing forth profound feelings of love and unity, within or without God. While interesting for many reasons, Prof. Habito's presentations were particularly helpful for strengthening our connections with the Divinity School.

In fall 2014, we hosted the well-known contemplative movement educator and former president of Naropa University, Barbara Dilley. About 50 participants attended each of two workshops exploring the relationship of dance and contemplative movement in theory and practice. Her visit, and the various conversations on pedagogy we had with her, was particularly helpful preparation for the course we taught at TCU on contemplative movement and reflection the following semester, to be discussed shortly. 
In Fall, 2015, we hosted Prof. Bill Barnard of Southern Methodist University, on his work with the Santo Daime tradition in Brazil and more generally with entheogens and contemplation. This was particularly interesting to Religious Studies faculty and students, and illustrated an understanding of Christianity quite novel to most. In spring 2016, our major speaker was John Dunne, the first holder of the Distinguished Chair in Contemplative Humanities at the University of Wisconsin, Madison, an endowed position created through their new Center for Healthy Minds. Dunne gave a public lecture on issues concerning contemplation and neuroscience, and held additional related discussions with students and faculty in our science programs (including our emerging medical school). Our Fall 2016 speaker was Barbara (Bobbi) Patterson of Emory University. She is an award winning teacher of contemplative pedagogy, and she gave both an inspiring lecture and instructive workshop to TCU faculty on this topic.

In addition to bringing in major speakers, it is noteworthy that during fall 2014 alone, TCU faculty gave five CS-related conference presentations off-campus in several different scholarly venues. This shows that our CS initiative has catalyzed not just the offering of informative on-campus events, but also research interest among the steering committee's faculty members. ${ }^{14}$ Two of these presentations were papers of my own, one of which was given at a CS conference organized by Louis Komjathy immediately before the 2014 American Academy of Religion Annual Meeting in San Diego, and another at the AAR meeting itself. Both of these papers were further developed at the 2015 DANAM meeting in Atlanta and in this article.

I should also note here that over the years, an array of sources have generously provided funds for our CS programming: our center for teaching excellence, various undergraduate departments (especially the Religion Dept.), the liberal arts college (known as AddRan), the university's Global Citizenship program, our Center for International Studies, the Asian Studies program and our affiliated divinity school (Brite).

\section{The first contemplative studies course at TCU}

Let me now turn to the most sustained and concentrated manifestation of our initiative at TCU thus far: our first curricular effort, formally titled Mindbodyness: Contemplative Movement and Reflection, a course that I co-taught in spring 2015 with a professor of modern dance, Susan Douglas Roberts. ${ }^{15}$ As an upper level directed study without core credit, it drew only nine students, but that modest number and the enthusiasm of the participants were actually very beneficial for this pilot effort. The course, held in a dance studio, met twice a week for 80 minutes. In most cases, the first half of the class was a contemplative movement practice led by my colleague (at different times, the movement included some combination of lying, sitting, and standing; walking, both straight and in circles/while turning; students moving solo, paired, or as a group; practicing various breathing styles; proceeding as an animal; and other actions). This was followed by journaling and conversation, and then we turned to lecture and discussion, which I or a guest led, about some aspect of "mindbodyness," with reference to the day's reading.

The course was loosely divided into several units: first we considered definitional and theoretical issues in CS, then various conceptions of mind and body in the modern West and in traditional Asia (including Indian Yoga, taijiquan, and Tibetan and Zen 
Buddhism; we also discussed Native American traditions). Some ideas were introduced by me, and others by an array of TCU faculty and off campus guests, including a highly appreciated visit from Judith Simmer-Brown of Naropa University. ${ }^{16}$ As the semester continued, students were assigned an increasing number of exercises, including weeklong practices of mindfulness meditation and the five basic Buddhist precepts. There were also day-long exercises of silence and focusing of awareness on "digital attachment," a practice of contemplative walking (beginning with John Francis's TED talk on silently "walking the earth"), ${ }^{17}$ and a labyrinth walk. Near the course end, we read Jeff Wilson's Mindful America (Wilson 2014), which raised important issues of cultural adaptation, appropriation, and commodification that the class participants found quite thought provoking.

The course concluded with a final contemplative project by each student, which included both movement and reflection, both indoors and outdoors. Some examples were slow walking amid Froghenge, the circular array of sculptured rocks in the center of campus, circling a building while looking at it closely and carefully, being present with trees as witnesses and elders, listening to "singing bowls," staying aware while doing repetitive motion, being with a partner with eyes open then moving in concert with one's eyes closed, slow rolling while attending to all parts of the body, walking a mini-labyrinth, and expressing gratitude to the body from feet to head while walking.

In class and in anonymous semester-end feedback, ${ }^{18}$ students expressed great appreciation for the course as providing new and different ways of knowing mind and body and their connection, both theoretically and on a "real, experiential" level. They especially valued learning what guest teacher Alejandro Chaoul called "meditation pills," tools to quiet and center themselves during the daily rush of university life. ${ }^{19}$ There was a striking emphasis on how much they welcomed and integrated simple and practical self-care skills of focused breathing and being present; this was especially important for and appreciated by the many seniors with an uncertain future after graduation. One said, beautifully, "this course became a refuge rather than a requirement."

But students also expressed frustration with the workload, both the amount of writing (weekly short papers, plus responses to the meditation exercises and the final project) and out of class practice, feeling (justifiably in retrospect) that we required too much in too concentrated a time. They and especially we also felt that there was insufficient time to adequately address all the material introduced in class. To address these issues, we will lighten the class writing and practice load, and plan 2 two-hour classes a week next time.

\section{Summary reflections}

With the aforementioned history in mind, I will provide my impressions of the development of TCU's CS initiative so far. I believe that our greatest success has been the creation of an interdisciplinary and highly collegial steering committee, which has stimulated reflection and enthusiasm among its members and become a core group which, as shown above, has brought attention to CS to a wide variety of university constituencies. There is no question that our university at large has a greater awareness of, and openness to, the benefits of contemplative inquiry than four years ago, during which time we have drawn the attendance of hundreds of faculty, staff, and students, many repeatedly. As just described, our efforts took successful curricular form for the first time last year. We have 
also begun to have a greater engagement with members of our associated Divinity School (Brite). Finally, through the generosity of an array of university sources, we have also had the opportunity to bring in some leading figures in this emerging movement, thus putting TCU on the map for CS.

Although we have reached hundreds of students (often with the strategic use of extra credit), perhaps our greatest disappointment has been the inability to create a selfsustaining student group which would originate student-focused activities. Because of this and the fact that students are dealing with a curriculum already full of requirements, we have had limited curricular success, but are heartened by the commitment and enthusiasm of the students who enrolled in the Mindbodyness course. We also think that gaining more regular involvement from a larger number of faculty in the sciences, including health sciences, especially with the beginning of our medical school, would contribute to the program's curricular success. Still, we have begun well and plan to continue to expand our influence carefully by documenting the value for faculty and students at each step and, most especially, by engaging in ongoing conversations at TCU and in the academy generally, about the role and benefits of CS.

\section{Part II: enhancing liberal arts education through contemplative studies}

I now turn to the second part of this paper, expanding on my thinking about the rationale for the broader principles underlying our program and particularly how CS can enrich the liberal arts. Thinking this through is especially important given the skepticism about CS in some quarters of academia. In this section then, I want to focus on justifying CS as a powerful and effective enhancement of liberal arts education.

One of the key assumptions behind the development of our initiative is that there are a wide variety of ways of knowing oneself and the world, and contemplative study and reflection is an important, and today often underappreciated, way to investigate and understand human existence. As a number of writers have pointed out, most university learning occurs through "third person" objective study, which is certainly important and valuable, but contemplative learning adds "first person" direct experience as a way to gain a more accurate (and "lived") understanding of both one's own and others' worldviews and practices, about which one can then critically reflect. ${ }^{20}$ It can also provide the opportunity to contemplate the validity of the possibility of "objective" third person study. ${ }^{21}$

Further, since contemplative inquiry has been important to many people in a large number of cultures, there are, naturally, diverse contemplative traditions and experiences. Another key assumption, therefore, is that, we should teach, to the extent appropriate to the class and our training, how this variety is understood and explained by practitioners of the various traditions we engage. This is part of a need for many academics to better appreciate that adherents or "insiders" of contemplative traditions themselves have a long history of critical analysis and argument about the nature of reality and the value of various introspective states, so we should attend to and communicate both the description of the states as well as the arguments. ${ }^{22}$ When done well, contemplative pedagogy can in fact be particularly effective in simultaneously increasing students' self-knowledge in and of their historical location along with their awareness of the breadth and depth of the understandings of those in other cultures and times. Such comprehension will lead to the classic liberal arts goals of more insight into and critical reflection on both self and other. 
It is also important to note that students themselves have urged us to develop contemplative methods in the classroom. Any teacher can observe that today's university students feel over-committed, over-worked, and overwhelmed. Thus, when first given the opportunity to meditate, many often think of such a practice as just one more daily task to complete. Yet many of us have seen that once students actually engage in meditation or other contemplative activity, they realize both how the exercises bring greater self-understanding and how useful they can be to their everyday life by reducing stress, improving mood, and bringing rest, ${ }^{23}$ which sometimes leads to hunger for more. ${ }^{24}$ As Fran Grace has discussed (See Grace 2011; Barbazat and Bush 2014), various empirical studies have begun to show that contemplative pedagogy provides an antidote to the anxiety, distraction, and academic pressure so many students feel, and there are measureable improvements in variables for mental, physical and emotional well-being. This, as well as academic improvement, is discussed in a very interesting study of the spiritual life of college students, Cultivating the Spirit: How College Can Enhance Students' Inner Lives (Astin et al. 2011). Here, the authors point out that while "knowing thyself" is understood to be central to liberal arts education, developing answers to meaning and purpose questions or discovering students' own beliefs and values gets little attention, especially when they are nervous about their future and finances in a difficult economy. In a seven-year (2003-10) study, the authors found that over their college careers, students became more personally spiritual and less formally religious, more caring, tolerant, and globally aware, and these qualities enhanced other "traditional" college outcomes: improved academics/GPA, leadership skills, psychological well-being and life satisfaction. One significant factor assisting this growth is meditation/reflection or any "inner work" that increased self-awareness. Indeed, the authors write that contemplative practices "are among the most powerful tools at our disposal for enhancing students' spiritual development (148)."

It bears repeating that the capacity to focus attention is particularly important given students' immersion in technology, social media and other ongoing diversions of modern life. ${ }^{25}$ Contemplative exercise raises awareness of everyday distractedness and the limits of the (overpraised) notion of multitasking, thus demonstrating the value of silence and quiet alertness so much a part of most contemplative traditions. It can also call into question the contemporary instrumentalist focus on "productivity" in and beyond work life. This focus points to trends in mainstream culture where meditation, and in particular various conceptions of "mindfulness," has become widespread in health care, corporations, and even the military. ${ }^{26}$ One hears of mindful leadership, parenting, therapy, sex, and marksmanship. As mentioned earlier, Jeff Wilson's recent book Mindful America (Wilson 2014) offers an excellent history of this cultural development. As his and others' writings demonstrate, academics are uniquely placed to add historical awareness and critical analysis to such practices. ${ }^{27}$

With students in mind then, let me again emphasize the benefits of contemplative practice for liberal education. ${ }^{28}$ As contemplation enhances the ability to concentrate and introspect, it increases the depth, quality, and strength of attention and mental discipline, as well as emotional control and awareness of body-mind interaction. ${ }^{29}$ It gives students the opportunity to reflect on and analyze "first person" experience-their own and others-in a classroom setting (for both peer and professor feedback). They can gain insight into how their perspective has been shaped and see new possibilities, 
both noticing and going beyond prior thought patterns. Finally, contemplative exercises offer students the opportunity to critically reflect on the meaning and value questions that they feel are too often ignored in the classroom, even or especially by professors in Religious Studies. ${ }^{30}$

\section{Contemplative studies and religious studies}

This conversation now leads me to a greater focus on how contemplative study and practice are especially useful in my home discipline of Religious Studies, where students are often for the first time introduced to long-standing and widely spread worldviews still insufficiently known in contemporary America. Religion professors can and should introduce students to the importance of a fuller understanding of the historical and cultural context of these worldviews, and how these perspectives influence human experience and interpretation-theirs and ours. Student understandings can then be enhanced by firsthand experience (as "participant-observers") of some basic exercises in various traditions (religious and modern secular) that have specialized in such "first person" inquiry. Responsible adaptation of methods drawn from those traditions enriches the liberal arts classroom, and different kinds of knowing can increase the capacity for critical analysis. ${ }^{31}$ That is, in evaluating what contemplative thinkers say, it is valuable to observe and analyze what and how we ourselves experience ("think about our thinking while we are thinking"), and compare and contrast that (even at an elementary level) with others' experience. To offer some brief examples: practicing mindfulness meditation or following (or not) the five basic Buddhist precepts for a week can illumine both the Buddhist tradition and the student's own mental patterns, ${ }^{32}$ as can movement practices in a dance department (as explored in the course discussed above), attending to art in a museum (vs. venerating an image in a church or temple), ${ }^{33}$ or contemplative walking (which could be usefully compared with "jogging" or "a stroll") in an anthropology course on Native American traditions. And while there has never been a single kind of yoga practice, one could also usefully contrast classical Hindu Patanjala Yoga with modern postural yoga exercise (See, for example, Sarbacker 2011).

Reflections on such theory and practice draw attention to what and how we study "religion(s)" and contemplative traditions, and illumine how differing issues and perspectives are important in different worldviews and models of reality. In sum, contemplative inquiry opens possibilities for critical thinking about both philosophical arguments and one's own and others' mental processes and contents. It can challenge prevailing theories, whether scientific, sectarian, or postmodern. Finally, by opening alternative views of human being and flourishing, contemplative study and practice offers new models and possibilities for thinking and living, thus addressing questions of meaning that arise for students, and all humans.

This is the promise of CS. There is, of course, need for more critical reflection on, and assessment of, the nature and significance of contemplation in general and contemplative pedagogy in particular, as I will indicate in the final section below.

\section{Bringing sufficient critique to contemplative studies}

Turning to a greater emphasis on critique of this emerging discipline, I am especially concerned about the importance of recognizing the specific time, place, and context of both any contemplative tradition and of its study, that is, the awareness of "their," as well 
as "our," historical locatedness. As Louis Komjathy and others have shown, historically, virtually all contemplative practice and experience has been religiously committed and tradition-based, and part of a path with a goal of transcending (or profoundly deepening insight into) this life (This is extensively discussed in Komjathy 2015). Worldviews are comprehensive (even if not always well-integrated), including an array of myths, rituals, doctrines, and ethics held by communities. When studying contemplative traditions, it is crucial to attend to how one's experience is shaped by one's cosmology (modern science vs. karma and samsara vs. heaven and hell), ideas of self (ego self, atman, soul) and ultimate reality (brahman, Dao, God or multiverse). What is the view of human embodiment and physiology? What are the associated ethical rules and prerequisites to contemplative practice, if any? The social institutions? Perhaps most important as it shapes these questions, what are the goals (liberation/salvation $^{34}$ vs. happiness and stress reduction)?

One of the merits of Religious Studies training is the awareness that all traditions change over time. Still, it is worth being reminded-and reminding others-that modern global awareness and comparative interests inevitably condition our thinking. This shows up in the definitions of "contemplation" itself; some focus on meditation and Asian religious traditions, others include prayer and scriptural study or certain kinds of movement, music, or painting, still others include any focused attention or mindful awareness. ${ }^{35}$ A modern pluralistic understanding is clearly seen in the common use of highly abstract and non-tradition specific terms like "pure experience," "spirituality," or "wisdom traditions." How does one negotiate the tension between the irreducible differences in historic contemplative traditions and today's common search for commonalities or "universals?" What in contemplation is "secular," what "spiritual" and what "religious?" And how should we deal with the modern concerns with race, class, and gender? Since contemporary traditions and worldviews are also inevitably in particular sociocultural locations, today's adherents always have interests and commitments, whether in theology, humanistic psychology, or natural science. Are these recognized and acknowledged? Having a position is inevitable, not a problem; the problem is not identifying or inquiring into one's position.

Further, most people who are being exposed to aspects of longstanding and complex contemplative traditions are not interested in and would not consider studying or practicing Asian religions in their ancient forms. But those of us who do such study (and possibly practice) face the question of how we should understand and address the high degree of appropriation, decontextualization, and commodification of most contemplative traditions today. An extended discussion of this topic is beyond the scope of this paper, but to mention some examples now under investigation: what, in the contemporary context, is "mindfulness," "yoga," or "Tantra," and how do these relate to earlier historical manifestations? ${ }^{36}$ Few practitioners today understand the originating traditions, have a holistic or prolonged practice, and submit to spiritual direction. Many in our therapeutically inclined culture are far more interested in the development, not cessation, of the ego self. While such studies are unlikely to be read by non-academics, Religious Studies scholars are uniquely positioned to note and describe an array of issues here. ${ }^{37}$ Some scholars are in fact making attempts to address these issues in popular journals such as Tricycle: The Buddhist Review. 
To conclude, I firmly believe (and hope to have shown at TCU) that Contemplative Studies can make an important new contribution to liberal education in broadening the ways of knowing available to students-but scholars, in and beyond Religious Studies, have an equally important job to keep to the critical inquiry and analysis that has long been at the heart of the liberal arts.

\section{Endnotes}

${ }^{1}$ See Fort 2013 and Fisher (Fisher, Kathleen: "Look Before You Leap: Re-considering Contemplative Pedagogy", forthcoming) along with responses by Andrew Fort and Louis Komjathy.Here are some points discussed more fully there: first and most important is the fact that like any group of scholars, and perhaps more than average in emerging fields, advocates of Contemplative Studies are a diverse group, and most that I know argue for CS as an enhancement of the valuable traditional liberal arts education, not a replacement for it. I agree that sometimes contemplative pedagogy can be insufficiently critical (as can "regular" teaching in many classrooms!) and that this legitimately puts off other scholars. Academic course work is not therapy, and our first job is to teach critical thinking and reflection, to help students understand religion(s) and themselves better, not help them feel good or be happy. Still, my experience is that contemplative exercises (with accurate information about others and critical reflection) usually do increase students' self-awareness and encourage openness to and engagement with other people and views.It's also worth noting that many of the figures in CS are not trained in Religious Studies, and I think those of us in this field have an important role to play in the development of CS. See Komjathy 2015. In the first two chapters, Komjathy gives a cutting edge introduction to, with a history and critical analysis of, CS.

${ }^{2}$ I have discussed this more extensively in Fort 2013. Concerning the definition of "liberal arts," there I write: "Liberal arts' or 'liberal education' has many qualities and purposes (overall, to provide the tools to inquire into the multi-level nature of human being and the universe), but the ones most relevant here include (1) reflective selfawareness, recognizing and critiquing one's beliefs and assumptions; (2) respectful and empathetic understanding of others (what I call 'mental migration' into other worldviews); (3) understanding that humans are socially and culturally conditioned, existing in and shaped by historical contexts; and (4) learning about various ways of thinking or modes of inquiry." Effective contemplative pedagogy would address each of these goals.For more on the definition of "contemplation," see footnote 43 here.

${ }^{3}$ Including meetings with staff members of the integrative medicine program of the MD Anderson Cancer Center and the director of the Rothko Chapel in Houston.

${ }^{4}$ The steering committee considered the eventual possibilities of secretarial help, office space, website, and university or other funding through grants and fundraising for a free standing program, but none of these were deemed necessary to begin, or have been pursued since. As will be noted later, we have used departmental, college, and university funding for speakers and materials such as flyers for events or to publicize upcoming courses with a contemplative component in the next semester.

${ }^{5}$ Including contemplation and counseling and contemplative exercises and social justice. One of the most successful presentations was a talk by a psychology professor on the cognitive neuroscience behind meditation, which included a Powerpoint illustrating anatomical changes that occur to the brain during meditation. A student then 
offered a well-researched and entertaining presentation on brain states during surfing and meditation. Over 70 students, faculty, and staff attended, listened, and practiced both silent and focused meditations.

${ }^{6}$ For example, a member of TCU's Student Development Services organized a panel on contemplative practices in contemporary Christianity. Speakers discussed the tradition of labyrinth building, the practice of centering prayer, integrating Asian practices like mantra chanting or Zen sitting with Christian contemplation, and more generally harmonizing the "secular," "spiritual" and "religious." In the question and answer period that followed, there was an interesting tension between some students whose views about our Calvinist fallen nature conflicted with the speakers' emphasis on the presence of God's love which they found in contemplation. We have also sponsored a conversation on Contemplation and Christian Ethics with a Brite Divinity School professor and a member of our steering committee.

${ }^{7}$ In the upper level Buddhism course, we include tonglen breathing and metta (loving kindness) meditations. For more ideas about practices, one might consult various articles in Simmer-Brown and Grace 2011 or Bush and Barbezat 2014.

${ }^{8}$ Kumare (https://en.wikipedia.org/wiki/Kumar\%C3\%A9, Accessed 15 November 2016) is about an Ivy League educated Indian-American filmmaker (Vikram Gandhi) who took on the persona of a Hindu guru and taught a group of followers in Phoenix. They embraced Gandhi as a true spiritual teacher, to an extent which surprised and even alarmed him, and taught him a great deal about himself as well.

${ }^{9}$ We screened Samsara (http://barakasamsara.com, Accessed 15 November2016) as part of both a weekly global cinema program at TCU and the Sociology and Anthropology Department's Sustainability Film Series. Filmed over five years and in twenty-five countries by Ron Fricke (director of photography for the 1982 film Koyaanisqatsi and director of the 1992 film Baraka), Samsara moves vividly but wordlessly from sacred grounds and natural wonders to disaster zones and meatpacking factories.For more on this movie (and our initiative), see Dennis 2015.

${ }^{10}$ Doing Time, Doing Vipassana (https://www.youtube.com/watch?v=WkxSyv5R1sg, Accessed 15 November 2016) shows how Kiran Bedi, the former Inspector General of Prisons in New Delhi, worked to transform the notorious Tihar Prison by teaching inmates the traditional Buddhist meditation practice of vipassana.

${ }^{11}$ Labyrinths as occasions for calm focus and reflection have a long history, of course, both within and beyond religious traditions (see, for example, http://labyrinthsociety.org, Accessed 15 November 2016). For example, over Easter weekend 2014, a temporary labyrinth was created on campus, organized and led by a professor of Anthropology, assisted by staff from our Office of Religious and Spiritual Life and Fort Worth church community members. The labyrinth was placed within a circular array of sculptured rocks in the center of campus affectionately known as Froghenge. Both faculty and students shared poignant writings about their experience walking the labyrinth, and the TCU student newspaper, the Skiff, covered it online and in its graduation issue (http://www.tcu360.com/campus/2014/04/32243.labyrinth-built-froghenge-help-students-find-peace-serenity.) Accessed 15 November 2016.

${ }^{12}$ These issues include how accountable members of the modern scientific community are to the traditions from which mindfulness and yoga arose (whether to use traditional terminology and acknowledge the roles of community and ethical behavior in 
practice) or how financing and the larger socio-economic environment condition their work (issues of class/race/gender and access/cost).

${ }^{13}$ As previously mentioned in note 1, see also Komjathy 2015.

${ }^{14}$ Prof. Dave Aftandilian in our Anthropology Department gave a paper at an Ecomusicologies conference in Asheville, NC referencing course meditations titled "From Hearing to Caring: The Role of Listening in Place-Based Pedagogy." Mark Dennis delivered a (now published) paper on our viewing and discussion of the film Samsara mentioned above to the International Society for Religion, Literature and Culture in Leuven, Belgium. Prof. Vanessa Miller presented a poster on "Creating CS in the Southwest" for the 2014 International Symposium for CS (organized by the Mind and Life Institute) in Boston.

${ }^{15}$ The syllabus can be found at http://personal.tcu.edu/afort/Mindbodynesssyl-3.16.15.pdf Accessed 19 Nov 2016.

${ }^{16}$ In addition to leading a Mindbodyness class session, she taught my Buddhism (and another world religion) class, led a seminar in contemplative writing for twenty five faculty and staff, and offered a public lecture on "Tibetan Buddhism: From Fringe to Fashion."

${ }^{17} \mathrm{https}: / /$ www.ted.com/talks/john_francis_walks_the_earth. Accessed 15 November 2016.

${ }^{18}$ The latter came from anonymous online end of semester student feedback forms (called SPOT for Student Perception of Teaching) used in all TCU courses.

${ }^{19}$ The idea of finding cues for brief respite or quiet time in daily life became a course theme, reinforced by other visitors.

${ }^{20}$ In addition to those scholars mentioned earlier, Harold Roth has been particularly eloquent and effective in writing about and developing such study. See, for example, Roth 2011. Through his leadership, Brown University now has a multidisciplinary CS initiative which considers the underlying philosophy, psychology, and phenomenology of human contemplative experience across cultures and times through a combination of these third person and first person approaches, both utilizing systematic investigation and ongoing critical reflection: See http://www.brown.edu/academics/contemplative-studies. Accessed 15 November 2016.For more resources, one can also consult the CS page on Louis Komjathy's website at the University of San Diego: http://home.sandiego.edu/ komjathy/Homepage_of_Louis_Komjathy/Contemplative_Studies.html.

Accessed 15 November 2016.

${ }^{21}$ On this issue, one might consult Jorge Ferrer's work on "participatory spirituality." See Ferrer (Ferrer, Jorge: Participation and the Mystery: Transpersonal Essays in Psychology, Education, and Religion.Albany: SUNY Press, forthcoming), as well as Ferrer and Sherman 2008.

${ }^{22}$ Given the breadth of traditions, no single source could cover this matter. However, one might consult colleagues or other specialists in specific traditions, and look at Komjathy 2015.

${ }^{23}$ See the comments by the Mindbodyness course participants above. Another good example of a course which illustrates the value of contemplative pedagogy is Haynes et al. 2013.

${ }^{24}$ That is, some students also look, with various degrees of urgency, for a nonneuroscientific explanation of unusual or "mystical" experiences, such as those described by Ehrenreich 2014 . 
${ }^{25} \mathrm{~A}$ good introduction to this topic can be found in Carr 2011.

${ }^{26}$ For a good popular example of this phenomenon, see Harris 2014.

${ }^{27}$ David McMahan's work has been particularly significant here. See McMahan 2008 and 2012.

${ }^{28}$ For a more extended argument, see Fort 2013, especially pp. 25-26.

${ }^{29}$ Scientific studies of aspects of contemplation, particularly in neuroscience, have recently increased dramatically. A good starting point is Ricard et al. 2014. A more advanced article is Lutz et al. 2015. To review the research more broadly, one might start at the centers at Emory (http://www.emory.edu/ECCS/research/index.html), Virginia (http://www.uvacontemplation.org/list/research), Wisconsin (http://centerhealthyminds.org/), and Brown (http://www.brown.edu/academics/contemplative-studies/research) Universities, or the work of David Vago at Harvard (http://davidvago.bwh.harvard.edu/), and Clifford Saron at UC Davis (http://saronlab.ucdavis.edu). The Mind and Life Institute (https://www.mindandlife.org/) is also pursuing this inquiry in a variety of ways. All accessed 15 November 2016.A particularly insightful investigation of the relation of Buddhism and neuroscience by the philosopher of mind Evan Thompson has recently appeared. See Thompson 2015.

${ }^{30}$ Student interest in the pursuit of questions about meaning and purpose, and the "great divide" they feel between their academic (critical analysis focused) and personal lives is explored at length in Walvoord 2008. She shows that many students want to develop or deepen their philosophy or life, within or outside a particular "spiritual path."

${ }^{31}$ For a brief overview of some of the ethical issues raised by contemplative pedagogy in the undergraduate classroom, see Fort 2013, pp. 29-30.

${ }^{32}$ For more on this, see Fort 2011.

${ }^{33} \mathrm{~A}$ good illustration of different ways of knowing in this context is to note how many objects originally meant to be contemplated and venerated "religiously" are now regarded primarily as historical artifacts or "works of art," to be viewed with a detached respect and perhaps to help create intercultural understanding and harmony.

${ }^{34}$ In which case, the proximate experience might be called diverse names like Krishna-prema, discerning God's grace, samadhi, or satori.

${ }^{35}$ In general, I use "contemplation" as a cross-cultural umbrella term, referring to a broad array of ways of knowing and focusing attention, often but certainly not always part of a religious tradition. It includes a wide variety of practices: sitting or walking meditation, simple attending to the present, breathing and other kinds of "mindfulness" practices, yogic postures, visualizations, silent prayer and group chanting, reflective selfinquiry, observing nature, certain kinds of journaling and reading, and many others.

${ }^{36}$ For the former, refer again to Wilson 2014. Regarding the latter two, David Gordon White's work is highly illuminating. See, for example, White 2012 and White 2003. Another valuable resource is Jain 2014.

${ }^{37}$ Again, Fisher (Fisher, Kathleen: "Look Before You Leap: Re-considering Contemplative Pedagogy", forthcoming). "Look Before You Leap," with accompanying responses would be useful here.

Competing interests

The author declares that he has no competing interests. 
References

Astin, A., A. Helen, and J. Lindblom. 2011. Cultivating the spirit: How college Can enhance Students' inner lives. San Francisco: Jossey-Bass.

Barbazat, D., and M. Bush (eds.). 2014. Current research on contemplative practice in contemplative practice in higher education. San Francisco: Jossey-Bass.

Bush, M., and D. Barbezat (eds.). 2014. Contemplative practices in higher education. San Francisco: Jossey-Bass.

Carr, N. 2011. The shallows: what the internet is doing to our brains. New York: W. W. Norton and Co.

Dennis, M. 2015. Contemplating 'SAMSARA' in samsara: film as medium for promoting mindfulness and meditative reflection on being human. Bulgyo munye yeon'gu (Journal of Buddhist Culture and Art) 5: 201-236.

Ehrenreich, B. 2014. Living with a wild god: a Nonbeliever's search for the truth about everything. New York: Hachette.

Ferrer, J.N., and J.H. Sherman (eds.). 2008. The participatory turn: spirituality, mysticism, religious studies. Albany: SUNY Press.

Fort, A. 2011. Awareness practices in an undergraduate Buddhism course. In Meditation and the classroom: contemplative pedagogy for religious studies, ed. J. Simmer-Brown and F. Grace, 179-186. Albany: SUNY Press.

Fort, A. 2013. Contemplative studies and the liberal arts. Buddhist-Christian Studies 33: 23-32.

Grace, F. 2011. Learning as a path, not a goal: contemplative pedagogy - its principles and practices. Teaching Theology and Religion 14(2): 99-124.

Habito, R. 2014. Zen and the spiritual exercises. New York: Orbis Books.

Harris, D. 2014. 10\% happier: How I tamed the voice in My head, reduced stress without losing my edge, and found selfhelp that actually works-a true story. New York: It Books.

Haynes, D.J., K. Irvine, and M. Bridges. 2013. The blue pearl: the efficacy of teaching mindfulness practices to college students. Buddhist-Christian Studies 33: 63-82.

Jain, A. 2014. Selling yoga: from counterculture to pop culture. New York: Oxford University Press.

Komjathy, L. (ed.). 2015. Contemplative literature: a comparative sourcebook on meditation and contemplative prayer. Albany: SUNY Press.

Lutz, A., A. Jha, J. Dunne, and C. Saron. 2015. Investigating the phenomenological matrix of mindfulness-related practices from a neurocognitive perspective. American Psychologist 70(7): 632-58.

McMahan, D. 2008. The making of Buddhist modernism. New York: Oxford University Press.

McMahan, D. 2012. Buddhism in the modern world. New York: Routledge.

Ricard, M., A. Lutz, and R.J. Davidson. 2014. Mind of the meditator. In Scientific American 311, vol. 5, 38-45.

Roth, H.D. 2011. Contemplative studies: Can It flourish in the religious studies classroom? In Meditation and the classroom: contemplative pedagogy for religious studies, 2011 th ed, ed. J. Simmer-Brown and F. Grace, 23-38. Albany: SUNY Press.

Sarbacker, S. 2011. Reflections on theory and practice: the case of modern yoga. In Meditation and the classroom: contemplative pedagogy for religious studies, ed. J. Simmer-Brown and F. Grace, 147-53. Albany: SUNY Press.

Simmer-Brown, J., and F. Grace (eds.). 2011. Meditation and the classroom: contemplative pedagogy for religious studies. Albany: SUNY Press.

Thompson, E. 2015. Waking, dreaming, being: self and consciousness in neuroscience, meditation, and philosophy. New York: Columbia University Press.

Walvoord, B. 2008. Teaching and learning in college introductory religion courses. Malden: Blackwell Publishing.

White, D.G. 2003. Kiss of the yogini: "tantric sex" in its south Asian contexts. Chicago: University of Chicago Press.

White, D.G. 2012. Yoga in practice. Princeton: Princeton University Press.

Wilson, J. 2014. Mindful America: meditation and the mutual transformation of Buddhism and American culture. New York: Oxford University Press.

\section{Submit your manuscript to a SpringerOpen ${ }^{\circ}$} journal and benefit from:

- Convenient online submission

- Rigorous peer review

- Immediate publication on acceptance

- Open access: articles freely available online

- High visibility within the field

- Retaining the copyright to your article

Submit your next manuscript at $>$ springeropen.com 